\title{
Optimal Decision and Coordination of Fresh E-Commerce Supply Chain Considering Double Loss
}

\author{
Shizhen Bai, Yang Lv 1 , and Zejun Liu \\ School of Management, Harbin University of Commerce, Harbin 150028, China \\ Correspondence should be addressed to Yang Lv; ly@s.hrbcu.edu.cn
}

Received 18 November 2021; Accepted 19 January 2022; Published 24 February 2022

Academic Editor: Lei Xie

Copyright ( $\odot 2022$ Shizhen Bai et al. This is an open access article distributed under the Creative Commons Attribution License, which permits unrestricted use, distribution, and reproduction in any medium, provided the original work is properly cited.

\begin{abstract}
Motivated by a large amount of quality loss and quantity loss of fresh products during transportation, this paper examines the effect of the double loss on decisions and profits by establishing models for a fresh e-commerce supply chain consisting of one online retailer and one third-party logistics provider. The online retailer sells fresh products and provides compensation for quantity loss. TPL's fresh-keeping effort during transportation can effectively reduce the double loss. We find that: (i) under the centralized model, the basic quantity loss rate and freshness sensitivity can improve fresh-keeping effort. The online retailer prefers price-raising strategies as the basic quantity loss rate increases and freshness sensitivity decreases. But, if fresh-keeping cost is within a certain range and the basic quantity loss rate is high enough, the online retailer prefers price reduction strategies. If fresh-keeping cost is high, as freshness sensitivity increases, the retailer first reduces prices and then raises prices. (ii) Under the decentralized model, as the basic quantity loss rate and freshness sensitivity increase, product price will increase. (iii) Centralized decision-making mode is more profitable to the supply chain. Furthermore, we design a "two-way cost sharing-revenue sharing" contract to coordinate the supply chain and achieve Pareto improvement.
\end{abstract}

\section{Introduction}

The convenience of online shopping attracts more people to choose online consumption [1]. Since 2011, many companies involve in the field of fresh e-commerce, and fresh e-commerce transactions have increased year after year. According to IResearch, the total volume of China's fresh e-commerce industry in 2020 reached 458.5 billion yuan, an increase of $64 \%$ over 2019, and it is expected to exceed one trillion by 2023 [2]. However, there exist many challenges at fresh e-commerce supply chains. First, there is a perishable characteristic of fresh products, resulting in a large amount of quality loss and quantity loss during transportation $[3,4]$. Quality loss is mainly reflected in the decline of freshness. According to the survey conducted by Bizrate Insights [5], product freshness is the foremost consideration for $55 \%$ of consumers. Quantity loss means that some products rot and deteriorate, and the effective quantity reaching consumers is lower than the purchased quantity [6]. The fresh e-commerce supply chain is different from the traditional one.
Consumers can apply for after-sales service online for quantity loss incurred during transportation and gain compensation according to the proportion of quantity loss. In China, the loss rate of fresh fruits and vegetables can reach $30 \%[7,8]$. The double loss of fresh products not only badly damages the income of online retailers but also results in an enormous waste of social resources. As a result, it is difficult for fresh e-commerce companies to realize sustainable development.

Given the high loss, more and more online retailers have in-depth cooperation with third-party logistics (TPL) providers [9]. TPL's fresh-keeping effort in transportation and distribution can simultaneously reduce product quality and quantity loss and increase online retailers' revenue [10]. For example, Jiangsu Noah's Ark Agricultural Technology Co. Ltd. has in-depth cooperation with SF Cold Chain, and SF Express provides a special fresh-keeping distribution channel for its hairy crab orders [11]. It is very important that TPL providers need to price the services they provide [12]. On one hand, it is related to the market share and profit 
of companies; on the other hand, it affects the pricing of fresh products through the transmission mechanism and then affects consumers' purchase intention and behavior, which will ultimately affect the profit situation of the TPL and the fresh e-commerce merchants. Meanwhile, in the absence of incentives, TPL is reluctant to actively increase fresh-keeping effort because it requires TPL to invest the corresponding cost.

Reasonable pricing decision for fresh products is also a challenge because the price is a key factor affecting consumer demand [13]. If the price is too high, it will lose too many customers with low reserve prices, reducing the appeal of fresh online consumption. But if the price is too low, the profit margin will be very small, not conducive to the sustainable development of fresh e-commerce [14]. Controlling the product price relative to the freshness has been the common practice [15-17]. Consequently, to meet the consumers' needs with different quality preferences and expand the business, companies will need to consider double loss pricing.

Moreover, product pricing and fresh-keeping efforts are decided by online retailers and TPL, respectively, and the two parties may rely on the efforts of the other party to freerider themselves. Both parties aim to maximize their interests, which may lead to deviation of optimal decision, thus reducing supply chain performance [18]. In academic research, a traditional cost sharing-benefit sharing contract is a common coordination method, but coordination cannot be achieved in this supply chain.

Based on this, the impacts of the quality loss and the quantity loss on optimal decisions and profits in the twoechelon supply chain under the e-commerce background will be significant. We will consider that the TPL's freshkeeping can control the double loss of fresh product and mainly investigate the following questions:

(1) How do the online retailer and TPL determine the optimal pricing and fresh-keeping effort decisions concerning the quality and quantity losses of fresh products?

(2) How have the basic quantity loss rate and the freshness sensitivity coefficient affected the optimal decisions and profits?

(3) Which decision-making mode is beneficial to the online retailer and the TPL?

(4) How to encourage the online retailer and the TPL to work together to achieve supply chain coordination and improve supply chain performance

We consider a fresh e-commerce supply chain comprising one online retailer and one TPL provider, where the online retailer sells fresh products and provides compensation services for quantity loss, and TPL is responsible for the preservation and transportation. The fresh-keeping effort invested by TPL can effectively reduce quality loss and quantity loss. Then, we formulate analytical models: a centralized decision-making model and a decentralized one, to provide optimal solutions for the supply chain when the double loss is present. We further investigate the change trends of the optimal solutions with the double loss.
The remainder of this paper is organized as follows. Section 2 provides a review of relevant literature. Section 3 shows the problem description. Section 4 gives a centralized decision-making model and a decentralized decision-making model and compares the results of the two models. Section 5 presents the supply chain decision model under the two-way cost sharing-revenue sharing contract. Section 6 uses some numerical examples to more intuitively explain our results. Section 7 summarizes the conclusions and discusses limitations and future research. All proofs are relegated to Appendix.

\section{Literature Review}

Based on the topic we discussed, our work is related to the following two aspects. One aspect is the study about deteriorating item supply chain; another aspect is the study about logistic outsourcing. Therefore, we will summarize the literature from the above two aspects.

2.1. Deteriorating Item Supply Chain Management. The literature on deteriorating item supply chain management is particularly rich, and most previous research papers on this issue focus on pricing, fresh-keeping effort decisions, and supply chain coordination. Dilupa et al. [15] studied pricing strategies for fresh products with time-variant quality in different market structures. Fan et al. [16] introduced consumer choice behavior to the dynamic pricing strategy of multibatch fresh agricultural products in line with real-time freshness. The above literature considered the perishable characteristics of fresh products but did not consider the impact of the fresh-keeping efforts of supply chain members on the loss of fresh products. To ensure the quality of fresh products, supply chain members are very important to fresh products. For instance, Yang and Tang [19] and Zheng et al. [20] compared the freshness of the products under different sales models. The above literature only considered the effect of preservation effort on quality loss but did not involve the effect of preservation effort on quantity loss. Zheng et al. [21] examined the impact of degradation rate on supply chain profits under quantity discount contracts.

However, quality loss and quantity loss capture the main features of fresh products in transportation and delivery [22]. To achieve supply chain coordination, many scholars have used different contracts to optimize the fresh-keeping and pricing decisions of supply chain members [23-28]. The above documents considered the cost of double loss in the decision-making but did not further study the specific impact of double loss on the optimal decisions. Online retailers urgently need to make corresponding decisions based on the difference in the loss of different fresh products.

As noted in the above works, consumers will not buy rotten, inedible products in the traditional supply chain. Our paper emphasizes that online retailers provide compensation services in the context of e-commerce in that fresh products' quantity loss cannot be avoided in transportation and distribution. Gu et al. [29] also assumed the online retailer promises to give a refund for each deteriorated product. Differently, we consider logistics outsourcing to 
TPL and examine the implications of losses for decisions and profits in the fresh e-commerce supply chain.

2.2. Logistic Service. To achieve the sustainable development of fresh e-commerce, a fresh supply chain should improve consumption experience such as logistics distribution and enhance consumers' confidence in product quality and safety [30, 31]. Sheng et al. [32] developed a trade-off between cost and transportation time for products with short life cycles. The research indicated that transportation service is one attribute of fresh-keeping service. However, we further discover the importance of the fresh-keeping service aiming to alleviate quality loss and quantity loss of fresh products. Qin et al. [33] investigated that during transportation, it is necessary to reduce temperature fluctuations as much as possible to reduce product deterioration.

TPL providers have professional fresh-keeping equipment and technology, and outsourcing TPL is a general trend. Cai et al. [34] believed that TPL's fresh-keeping effort can increase the value of fresh products and eliminate the two "double marginal effects" in the supply chain through contracts. On this basis, $\mathrm{Wu}$ et al. [35] and Yu et al. [6] considered the logistics service level of TPL to affect the quality and quantity of fresh products at the same time and studied the optimal decision-making. Yu et al. [36] discussed the impact of the outsourcing model of fresh agricultural products on supply chain decisions and profits. Ma et al. [37] showed that TPL will exaggerate demand and cause damage to suppliers' interests under asymmetric demand information. Song et al. [38] explored the coordination of a fresh e-commerce supply chain with TPL and community convenience store's participation in decisions. Giri et al. [39] explored how the business organization decides to outsource a proportion of their supply chain operations. Liu et al. [40] constructed logistics outsourcing strategies from the perspective of the evolutionary game.

In summary, this paper contributes to several streams of literature. First, we integrate quality loss and quantity loss into a framework for a fresh e-commerce supply chain and study the pricing and fresh-keeping effort decisions under the centralized and decentralized game models, respectively. Second, we characterize the sensitivity of equilibrium decisions and profits to the basic quantity loss and freshness. Then, we compare the optimal decisions and profits under the two models. We find that decentralized decision-making will lead to deviations between fresh-keeping effort and price decisions and ultimately lead to a decline in the overall profit of the supply chain. Finally, we design a two-way costsharing and revenue-sharing contract that can facilitate the coordination between the online retailer and the TPL.

\section{Problem Description}

We consider a fresh e-commerce supply chain where an online retailer sells fresh products with the unit cost of $c$ at a unit retail price $p$. The fresh-keeping effort is provided by a TPL whose unit fresh-keeping cost is $c_{l}$, and the unit logistic service price is $p_{l}\left(p_{l}>c_{l}\right)$ paid by the online retailer. TPL's fresh-keeping investment can largely reduce quality loss and quantity loss. Consumers can apply for after-sales service online and obtain compensation at the payment price $p$ according to the proportion of quantity loss. Denote the unit quantity loss cost as $s$, where $s>p$ illustrates additional costs were incurred for the after-sale service.

Let $e$ measure the level of fresh-keeping effort invested by TPL. We assume that the fresh-keeping cost $C(\tau)=1 / 2 \mu e^{2}$ is incurred to the TPL, where $\mu$ reflects the service cost efficiency. The quadratic function of service cost is generally used in the marketing literature and operations management, reflecting the increase in the marginal cost of freshkeeping cost $[41,42]$.

According to the research of $\mathrm{Yu}$ and Xiao [6], the quantity loss rate is of the form $(1-e) r$, where $r(0 \leq r \leq 1)$ is the quantity loss rate without fresh-keeping effort, that is, basic quantity loss rate. It reflects the perishability of the product; the larger the $r$, the higher the perishability of the product. As the value of rotten products is extremely low and sometimes even requires disposal costs, it is assumed that the residual value of rotten products is zero.

According to the research of Cai et al. [22], let the freshness level be $\theta$. We assume $\theta=\theta_{0} e$, where the initial freshness state before transportation is $\theta_{0}\left(0 \leq \theta_{0} \leq 1\right) . \theta_{0}$ is a strictly increasing function with respect to $e$.

The market demand varies with the selling price and the freshness level. We assume that the market demand functional form is $D=\alpha-b p+\gamma \theta$, where $\alpha$ represents the market size and $b$ and $\gamma$, respectively, represent the sensitivity of the market demand to the selling price and the freshness level.

Without fresh-keeping effort, the online retailer's unit selling price $p$ should be higher than the unit cost to make a positive profit, that is, $p>c+c_{l}+s r$. Similarly, to ensure that the market demand is positive when there is no freshkeeping effort, that, $\alpha-b p>0$, the moduli should satisfy $\alpha-b\left(c+c_{l}+s r\right)>\alpha-b p>0$. Thus, we can propose that the moduli satisfy $\alpha-b\left(c+c_{l}+s r\right)>0$.

To investigate whether the online retailer and the TPL adopt a cooperative model, we recognize two decisionmaking models: centralized model and decentralized model. We will examine the effect of quality loss and quantity loss of fresh products on optimal decisions and profits. We also compare the optimal fresh-keeping effort, logistic service price, and retail price in the centralized and decentralized model and design a contract to coordinate the fresh e-commerce supply chain. Figure 1 describes the supply chain structure. After consumers confirm orders, the online retailer prepares the goods, and TPL is responsible for freshkeeping and delivery services. If there is a loss in quantity, consumers can apply for compensation services online and receive corresponding compensation.

We summarize all nations in Table 1.

\section{Model and Analysis}

The supply chain decision-making problem is usually looked at from the viewpoints of centralized and decentralized organization settings. In the following, this paper first takes 


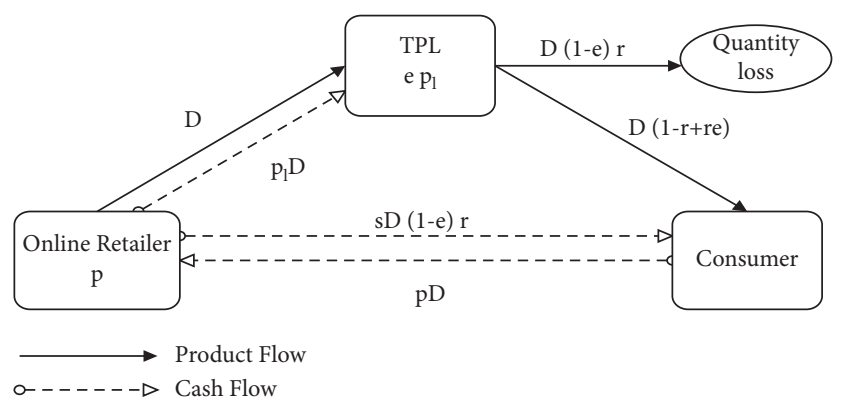

Figure 1: The supply chain structure.

the centralized model as the benchmark model, then analyzes the impact of freshness sensitivity and basic quantity loss rate on optimal decision and profit, and compares with the decentralized model to demonstrate the necessity of building a coordination model.

4.1. Centralized Model (C). Under the centralized decisionmaking model, the online retailer and TPL are regarded as one decision-making organization. From the perspective of maximizing the profit of the supply chain system, the retail price of fresh products $p$ and the fresh-keeping effort level $e$ are together decided.

Then the profit of the supply chain system can be obtained as follows:

$$
\pi_{S C}^{C}=\left(p-c-c_{l}\right) D-\frac{1}{2} \mu e^{2}-s D(1-e) r .
$$

Lemma 1. Assume $\mu>\max \left(\mu^{\mathrm{C} 2}, \mu^{\mathrm{C} 3}\right)$, then there exist the equilibrium decisions, $\left(e^{C *}, p^{C *}, D^{C *}, \pi_{S C}^{C *}\right)$, as follows:

$$
\begin{aligned}
e^{C *}= & \frac{\left(b s r+\gamma \theta_{0}\right)\left(\alpha-b c-b c_{l}-b s r\right)}{2 b \mu-\left(b s r+\gamma \theta_{0}\right)^{2}}, \\
p^{C *}= & \frac{\left(\mu-s r\left(b s r+\gamma \theta_{0}\right)\right)\left(\alpha-b c-b c_{l}-b s r\right)}{2 b \mu-\left(b s r+\gamma \theta_{0}\right)^{2}} \\
& +c+c_{l}+s r, \\
D^{C *}= & \frac{b \mu\left(\alpha-b c-b c_{l}-b s r\right)}{2 b \mu-\left(b s r+\gamma \theta_{0}\right)^{2}}, \\
\pi_{S C}^{C *}= & \frac{\mu\left(\alpha-b c-b c_{l}-b s r\right)^{2}}{2\left(2 b \mu-\left(b s r+\gamma \theta_{0}\right)^{2}\right)}+c+c_{l}+s r,
\end{aligned}
$$

where $\mu^{C 2 *}=s r\left(b s r+\gamma \theta_{0}\right)$ and $\mu^{C 3 *}=\left(b s r+\gamma \theta_{0}\right)$ $\left(\alpha-b c-b c_{l}+\gamma \theta_{0}\right) / 2 b$.

4.2. Decentralized Model (D). Under the decentralized decision-making model, the online retailer and TPL make optimal decisions based on the principle of maximizing their respective profits. The game process between the two parties is as follows: first, TPL provides the online retailer with the unit logistics service price $p_{l}$ and the fresh-keeping effort level $e$; then, the online retailer decides the retail price $p$ according to the logistics service price $p_{l}$ and the promised fresh-keeping effort level $e$.

The online retailer and TPL's profit functions are as follows:

$$
\begin{aligned}
& \pi_{R}^{D}=\left(p-c-p_{l}\right)\left(\alpha+\gamma \theta_{0} e-b p\right)-s\left(\alpha+\gamma \theta_{0} e_{l}-b p\right)(1-e) r, \\
& \pi_{L}^{D}=\left(p_{l}-c_{l}\right)\left(\alpha+\gamma \theta_{0} e-b p\right)-\frac{1}{2} \mu e^{2} .
\end{aligned}
$$

Lemma 2. Assume $\mu>\max \left(\mu^{D 2}, \mu^{D 3}\right)$, then there exist the equilibrium decisions, $\left(e^{D *}, p_{l}^{D *}, p^{D *}, D^{D *}, \pi_{R}^{D *}, \pi_{L}^{D *}, \pi_{S C}^{D *}\right)$, as follows:

$$
\begin{aligned}
e^{D *}= & \frac{\left(b s r+\gamma \theta_{0}\right)\left(\alpha-b c-b c_{l}-b s r\right)}{4 b \mu-\left(b s r+\gamma \theta_{0}\right)^{2}}, \\
p_{l}^{D^{*}=}= & \frac{2 \mu\left(\alpha-b c-b c_{l}-b s r\right)}{4 b \mu-\left(b s r+\gamma \theta_{0}\right)^{2}}+c_{l}, \\
p^{D^{*}}= & \frac{\left(3 \mu-s r\left(\gamma \theta_{0}+b s r\right)\right)\left(\alpha-b c-b c_{l}-b s r\right)}{4 b \mu-\left(b s r+\gamma \theta_{0}\right)^{2}} \\
& +c+c_{l}+s r, \\
D^{D *}= & \frac{b \mu\left(\alpha-b c-b c_{l}-b s r\right)}{4 b \mu-\left(b s r+\gamma \theta_{0}\right)^{2}}, \\
\pi_{R}^{D^{*}=} & \frac{b \mu^{2}\left(\alpha-b c-b c_{l}-b s r\right)^{2}}{\left(4 b \mu-\left(b s r+\gamma \theta_{0}\right)^{2}\right)^{2}}, \\
\pi_{S C}^{D^{*}=} & \pi_{R}^{D^{*}+\pi_{L}^{D *}} \\
\pi_{L}^{D^{*}}= & \frac{\mu\left(\alpha-b c-b c_{l}-b s r\right)^{2}}{2\left(4 b \mu-\left(b s r+\gamma \theta_{0}\right)^{2}\right)}
\end{aligned}
$$

where $\mu^{D 2 *}=s r\left(b s r+\gamma \theta_{0}\right) / 3$ and $\mu^{D 3 *}=\left(b s r+\gamma \theta_{0}\right)$ $\left(\alpha-b c-b c_{l}+\gamma \theta_{0}\right) / 4 b$.

Proposition 1. The optimal decisions and profits of both parties will increase as the potential market size $\alpha$ increases in the centralized model and decentralized model.

From Proposition 1, we obtain that under the centralized and decentralized model, the product retail price and freshkeeping effort level increase with the increase of the potential market size $\alpha$. This shows that the market size will help improve the fresh-keeping effort. The overall profit of the supply chain is also positively correlated with the market size. Therefore, how to develop and expand the market size of fresh food e-commerce is a common concern for online retailers and TPL.

4.3. The Influence of Decision-Making Mode on the Equilibrium Outcome. In this section, we first analyze the effects of 
TABLE 1: List of notations.

\begin{tabular}{lc}
\hline Notation & Description \\
\hline$c$ & Parameters \\
$c_{l}$ & Unit production cost of the online retailer \\
$s$ & Unit transportation cost of the TPL \\
$r$ & Unit quantity loss cost of the online retailer \\
$\alpha$ & Loss rate of quantity without fresh-keeping effort service, i.e., basic quantity loss rate, $r \in[0,1]$ \\
$b$ & The market scale \\
$\gamma$ & The sensitivity of the market demand to the retail price, referred to as price sensitivity \\
$D$ & The sensitivity of the market demand to the freshness level, referred to as freshness sensitivity \\
$\theta_{0}$ & The market demand \\
$\theta$ & The freshness level before transportation \\
$\mu$ & The freshness level; $1-\theta$ reflects the quality loss \\
$\pi_{R}$ & The fresh-keeping cost factor \\
$\pi_{L}$ & The online retailer's profit \\
$\pi_{S C}$ & The TPL's profit \\
\hline & The profit of the supply chain \\
$e$ & Decision variables \\
$p_{l}$ & The fresh-keeping effort level, $e \in[0,1]$ \\
$p$ & The TPL's logistic service price, $p_{l}>c_{l}$ \\
\hline
\end{tabular}

basic quantity loss rate and freshness sensitivity on the optimal decisions. Then, based on analysis, we compare the equilibrium decisions and profits under the centralized and decentralized model.

Proposition 2. The impact of the basic quantity loss rate on optimal decisions and profits under the centralized model is $d e^{C *} / d r>0, d D^{C} / d r<0, d \pi_{S C}^{C *} / d r<0$. For the retail price, when $\gamma \theta_{0} K / b<\mu<K\left(2 K+\sqrt{4 K^{2}+9 \gamma^{2} \theta_{0}^{2}}\right) / 9 b$, if $0<r<r_{1}$, we have $d p^{C^{*}} / d r>0$; if $r_{1}<r<r_{2}$, we have $d p^{C^{*}} / d r<0$. When $\quad \mu \in\left(\left(b s r+\gamma \theta_{0}\right) K / 2 b, \gamma \theta_{0} K / b\right) \cup(K(2 K+$ $\left.\left.\sqrt{4 K^{2}+9 \gamma^{2} \theta_{0}^{2}}\right) / 9 b,+\infty\right)$, we have $d p^{C^{*}} / d r>0$, where $K=\alpha-b c-b c_{l}+\gamma \theta_{0}, \quad r_{1}=\left(b \mu-\gamma^{2} \theta_{0}^{2}\right) K+b \mu \gamma \theta_{0}-$ $\sqrt{b \mu\left(b \mu-2 \gamma^{2} \theta_{0}^{2}\right)\left(K^{2}-2 b \mu\right)} / b s \quad\left(b \mu+\gamma \theta_{0} K\right)$, $r_{2}=\sqrt{4 b \mu+\gamma^{2} \theta_{0}^{2}}-\gamma \theta_{0} / 2 b s$.

Proposition 2 reveals that under the centralized decisionmaking model, the optimal fresh-keeping effort is positively correlated with the basic quantity loss rate, and the market demand and the total profit of the supply chain are negatively correlated with the loss rate. With the increase of the basic quantity loss rate, the higher the requirements for the freshness level, the TPL will increase the level of fresh-keeping effort to ensure that the effective quantity of the product reaches the consumers. This is because the greater the quantity loss rate means the higher the compensation ratio. The lower the operational efficiency of the supply chain, the lower the profit level of the supply chain. Therefore, the supply chain should encourage TPL to increase the level of fresh-keeping effort, reduce the waste of physical resources, and improve the overall profit level of the supply chain.

Under the centralized decision-making model, the relationship between the optimal selling price of fresh products and the basic quantity loss rate is as follows: when the freshkeeping cost coefficient is low or high $\left(\mu \in\left(\left(b s r+\gamma \theta_{0}\right)\right.\right.$
$\left.\left.K / 2 b, \gamma \theta_{0} K / b\right) \cup\left(K\left(2 K+\sqrt{4 K^{2}+9 \gamma^{2} \theta_{0}^{2}}\right) / 9 b,+\infty\right)\right)$, the optimal selling price is positively correlated with the loss rate. This shows that when product preservation is more economical, as the quantity loss rate increases, the fresh supply chain chooses to increase the investment in preservation effort while choosing a price increase strategy. At this time, the positive impact of improving product freshness on demand is greater than the negative impact of raising the price on demand, so the supply chain will raise the price to capture more profits. When preservation is more expensive, a higher loss rate can increase the level of preservation effort and at the same time increase the cost of the preservation effort. The supply chain will increase the price to make up for the cost of preservation. When the preservation cost coefficient is within a certain range $\left(\gamma \theta_{0} K / b<\mu<K\left(2 K+\sqrt{4 K^{2}+9 \gamma^{2} \theta_{0}^{2}}\right) / 9 b\right)$, the increase in the basic quantity loss rate will cause the supply chain to increase the product price first and then reduce the price. When the quantity loss rate is low, as the loss rate increases, the supply chain will increase the preservation effort while increasing the product price. This is because the effect of the preservation is weak at this time, the compensation cost changes little, the preservation cost increases rapidly, and the supply chain will choose a price increase strategy. When the loss rate is higher than a certain threshold, the more obvious the effect of keeping freshness in controlling the loss of quantity, the lower the compensation cost, which in turn makes the supply chain choose a price reduction strategy.

Proposition 3. The impact of the basic quantity loss rate on optimal decisions and profits under the decentralized model is: for the fresh-keeping effort, when $\mu<K\left(49 K-8 \gamma \theta_{0}+\right.$ $7 \sqrt{49 K^{2}-16 \gamma \theta_{0}\left(K-4 \gamma \theta_{0}\right)} / 384 b$, we have $d e^{D *} / d r>0$. When $\mu>K\left(49 K-8 \gamma \theta_{0}+7 \sqrt{49 K^{2}-16 \gamma \theta_{0}\left(K-4 \gamma \theta_{0}\right)}\right) /$ $384 b$, if $0<r<r_{11}$, we have $d e^{D *} / d r>0$; if $r_{11}<r<r_{22}$, we have $\quad d e^{D *} / d r<0 . \quad d p_{l}^{D *} / d r<0, d p^{D^{*}} / d r>0$, 
$d D^{D *} / d r<0, d \pi_{R}^{D^{*}} / d r<0, d \pi_{L}^{D^{*}} / d r<0$, where $r_{11}=4 b \mu-2$ $\sqrt{b \mu\left(4 b \mu-K^{2}\right)}-\gamma \theta_{0} K / b s K, r_{22}=\sqrt{12 b \mu+\gamma^{2} \theta_{0}^{2}}-\gamma \theta_{0} / 2 b s$.

Proposition 3 shows that under decentralized decisionmaking model, the relationship between the fresh-keeping effort level and the basic quantity loss rate is affected by the dual effects of the fresh-keeping cost coefficient and the loss rate: when the fresh-keeping cost coefficient is low $\left(\mu<K\left(49 K-8 \gamma \theta_{0}+7 \sqrt{49 K^{2}-16 \gamma \theta_{0}\left(K-4 \gamma \theta_{0}\right)} / 384 b\right)\right.$,

TPL will improve fresh-keeping effort to meet consumer demand. When the fresh-keeping cost coefficient is high $\left(\mu>K\left(49 K-8 \gamma \theta_{0}+7 \sqrt{49 K^{2}-16 \gamma \theta_{0}\left(K-4 \gamma \theta_{0}\right)} / 384 b\right)\right.$, the fresh-keeping effort shows a trend of first increasing and then decreasing with the basic quantity loss rate increasing. The product sales price is positively correlated with the basic quantity loss rate. The logistics service price, market demand, online retailer profit, TPL profit, and the loss rate are all negatively correlated. As the loss rate increases, TPL will lower the logistics services price to ease the loss of demand. At this time, the online retailer will increase product sales prices by considering the increase in compensation costs. Retail price increases will have a greater negative impact on demand. Market demand is significantly reduced, so the profits of the online retailer and TPL decrease as the loss rate increases.

Proposition 4. The impact of freshness sensitivity coefficient on optimal decisions and profits under the centralized model is: $d e^{C *} / d \gamma>0, d \pi_{S C}^{C^{*}} / d \gamma>0$; for the retail price, when $\mu \leq s r\left(\sqrt{\left(\alpha-b c-b c_{l}-b s r\right)^{2}+4 b^{2} s^{2} r^{2}}+2 b s r\right) / 2$, we have $d p^{C^{*}} / d \gamma<0$. When $\mu>s r\left(\sqrt{\left(\alpha-b c-b c_{l}-b s r\right)^{2}+4 b^{2} s^{2} r^{2}}\right.$ $+2 b s r) / 2$, if $0<\gamma<\gamma_{1}$, we have $d p^{C^{*}} / d \gamma<0$; if $\gamma_{1}<\gamma<\gamma^{*}$, we have $d p^{C^{*}} / d \gamma>0$, where $\gamma_{1}=\mu-b s^{2} r^{2}-$ $\sqrt{\mu\left(\mu-2 b s^{2} r^{2}\right)} / s r \theta_{0}$ and $\gamma^{*}=\sqrt{8 b \mu+\left(\alpha-b c-b c_{l}-b s r\right)^{2}}$ $+b c+b c_{l}-\alpha-b s r / 2 \theta_{0}$.

Proposition 4 illustrates that under the centralized decision-making model, the optimal fresh-keeping effort of fresh products and the total profit of the supply chain are positively related to the freshness sensitivity. As the freshness sensitivity increases, the supply chain will increase fresh-keeping effort to ensure product freshness. This is because the greater the freshness sensitivity coefficient means that the reduction in freshness will have a greater impact on the loss of demand. Therefore, the supply chain will increase the level of freshness fresh-keeping effort to alleviate the loss of demand for fresh products.

Under the centralized decision-making model, the relationship between the product sales price and freshness sensitivity coefficient is as follows: When the fresh-keeping cost coefficient is low $\left(\mu>s r\left(\sqrt{\left(\alpha-b c-b c_{l}-b s r\right)^{2}+4 b^{2} s^{2} r^{2}}\right.\right.$ $+2 b s r) / 2$ ), the price and the freshness sensitivity coefficient are negatively correlated. This shows that when the freshness preservation of fresh products is more economical, as the freshness sensitivity coefficient increases, the online retailer increases the investment in fresh-keeping effort while choosing a price reduction strategy to stimulate the market demand. However, when the fresh-keeping cost is high $(\mu>s r$ $\left.\left(\sqrt{\left(\alpha-b c-b c_{l}-b s r\right)^{2}+4 b^{2} s^{2} r^{2}}+2 b s r\right) / 2\right)$, the online retailer will face the decision of whether to increase the retail price. When the freshness sensitivity coefficient is low $\left(0<\gamma<\gamma_{1}\right)$, the online retailer chooses a price reduction strategy, which shows that when the freshness sensitivity coefficient is low, consumers pay more attention to product prices than product quality, so the online retailer is more inclined to reduce prices to stimulate products market demand. When the freshness sensitivity coefficient is higher than a certain critical value $\left(\gamma_{1}<\gamma<\gamma^{*}\right)$, as the freshness sensitivity coefficient increases, the online retailer will increase fresh-keeping effort and retail prices at the same time. This is because the product freshness sensitivity coefficient is at a high level, which means that increasing the freshness effort level has a greater positive impact on demand. Coupled with higher fresh-keeping costs, the online retailer chooses to increase prices.

Proposition 5. The impact of freshness sensitivity coefficient on optimal decisions and profits under the decentralized model is $d e^{D *} / d \gamma>0, d p_{l}^{D^{*}} / d \gamma>0, d p^{D^{*}} / d \gamma>0, d \pi_{R}^{D^{*}} /$ $d \gamma>0, d \pi_{L}^{D^{*}} / d \gamma>0$.

Proposition 5 states that the optimal fresh-keeping effort level, logistics service prices, retail prices, online retailer profits, TPL profits, and freshness sensitivity coefficient are all positively correlated under the decentralized decision-making model. As the freshness sensitivity coefficient increases, TPL will increase the fresh-keeping effort level and the logistics services price, effectively reducing the cost of compensation and expanding market demand at the same time. Online retailers will increase product prices. Compared with the positive impact of freshness increase on demand, product price increases have a less negative impact on demand. Market demand increases with the increase in freshness sensitivity, realizing the supply chain profit growth on both parties.

Proposition 6. The impact of freshness sensitivity coefficient on optimal decisions and profits under the decentralized model is $e^{C *}>e^{D *}, p^{C^{*}}<p^{D^{*}}, D^{C}>D^{D}, \pi_{S C}^{D^{*}}<\pi_{S C}^{C^{*}}$.

Proposition 6 shows that compared with the decentralized decision-making model, the centralized decision-making model can decide on fresh e-commerce supply chain reach the optimal state. Under the centralized decision-making model, online retailer sets the lower selling price, and TPL will invest a higher level of fresh-keeping effort to expand market demand and bring high profits with the joint efforts of both parties. Therefore, centralized decision-making is an ideal model. However, in reality, the goal of both parties is to maximize their profits through independent decision-making. Online retailers will increase sales prices, and consumers will buy such fresh products at a higher price, which increases the pressure on product consumption and reduces consumption. Consumers' enthusiasm for consumption further restricts the development of fresh e-commerce. At the same time, TPL considers that the preservation cost will reduce the preservation effort level, the consumption of fresh products will increase in the transportation process, and consumers will have poor shopping experiences and low perceived value. 
Finally, market demand and total supply chain profit under decentralized decision-making are less than centralized decision-making.

Therefore, they should make improvements to centralized decision-making from both the selling price of fresh products and the level of fresh-keeping effort when designing contracts between online retailers and TPL.

\section{Coordinating the Supply Chain $(H)$}

In the fresh e-commerce supply chain, TPL invests in the fresh-keeping effort, which not only can reduce the quantity loss of fresh products in the transportation process but also can improve the freshness of the products. The improvement of product quality is equivalent to increasing the profit of online retailers. The online retailer has an incentive to share part of the fresh-keeping cost and share a certain percentage of sales revenue with TPL to encourage TPL to improve the fresh-keeping effort. Based on this, we first adopt a costsharing and benefit-sharing contract $H\left(\phi, h_{e}\right)$, that is, online retailers share the $h_{e}\left(0<h_{e}<1\right)$ proportion of the freshkeeping cost of TPL and share $\phi$ proportion of the sales revenue to TPL. However, after verification, we found that a simple cost-sharing revenue-sharing contract cannot achieve fresh e-commerce supply chain coordination, nor can it achieve Pareto improvement.

Hence, we also consider that the online retailer is solely responsible for compensation costs under the decentralized decision-making model. To avoid free-riding behavior in TPL, TPL needs to share part of the compensation cost. In this context, we analyze the "two-way cost-sharing and revenue-sharing" contract $H\left(\phi, h_{e}, h_{r}\right)$, that is, the online retailer decides to share the $h_{e}\left(0<h_{e}<1\right)$ proportional fresh-keeping cost of TPL and share the $\phi$ proportion of sales revenue to TPL; TPL shares the $h_{r}\left(0<h_{r}<1\right)$ proportion of the online retailer's compensation cost.

Under coordination contract, the online retailer and TPL's profit functions are as follows:

$$
\begin{aligned}
& \pi_{R}^{H}=\left(\phi p-c-p_{l}\right) D-\left(1-h_{r}\right) s D(1-e) r-\frac{1}{2} h_{e} \mu e^{2}, \\
& \pi_{L}^{H}=\left(p_{l}-c_{l}+(1-\phi) p\right) D-h_{r} s D(1-e) r-\frac{1}{2}\left(1-h_{e}\right) \mu e^{2} .
\end{aligned}
$$

Lemma 3. Under coordination contract, the optimal decisions and profits are as follows:

$$
\begin{aligned}
& \begin{aligned}
e^{H *}= & \frac{\alpha \phi^{2}\left(F(1-\phi)+h_{r} E\right)+\phi^{2} b F\left(p_{l}-c_{l}-h_{r} s r\right)}{2 \phi^{2} b \mu\left(1-h_{e}\right)+E^{2}\left(1-h_{r}\right)^{2}+\phi\left(\phi F-h_{r} E\right)^{2}-\phi^{2} F^{2}-\phi E^{2}}+ \\
& +\frac{b E\left(\operatorname{sr}\left(\left(1-h_{r}\right)^{2}-\phi\left(1-h_{r}^{2}\right)\right)+\left(1-h_{r}\right)\left(c+p_{l}\right)-\phi\left(c+c_{l}+h_{r} p_{l}\right)\right)}{2 \phi^{2} b \mu\left(1-h_{e}\right)+E^{2}\left(1-h_{r}\right)^{2}+\phi\left(\phi F-h_{r} E\right)^{2}-\phi^{2} F^{2}-\phi E^{2}}, \\
p^{H *}= & \frac{2 \phi\left(\mu-\mu h_{e}-F h_{r} s r\right) A+s r E\left(1-h_{r}\right)\left(\left(1-h_{r}\right)\left(\alpha+c_{l}\right)-\alpha \phi\left(1+2 h_{r}\right)-h_{r} b c-b p_{l}\right)}{2\left(2 \phi^{2} b \mu\left(1-h_{e}\right)+E^{2}\left(1-h_{r}\right)^{2}+\phi\left(\phi F-h_{r} E\right)^{2}-\phi^{2} F^{2}-\phi E^{2}\right)} \\
& +\frac{F s r\left(1-h_{r}-\phi\right) B+\phi F^{2}\left((1-2 \phi)\left(h_{r} s r-p_{l}\right)-(1-\phi)(c+s r)-\phi c_{l}\right)}{2\left(2 \phi^{2} b \mu\left(1-h_{e}\right)+E^{2}\left(1-h_{r}\right)^{2}+\phi\left(\phi F^{2}-h_{r} E\right)^{2}-\phi^{2} F^{2}-\phi E^{2}\right)}, \\
\text { A }=\phi \alpha+b c+b p_{l}+E-h_{r} E, B=-\phi \alpha+b c+ & \pi_{R}^{H^{*}}=\frac{\phi \mu\left(\alpha-b c-b c_{l}-b s r\right)^{2}}{2\left(2 b \mu-\left(b s r+\gamma \theta_{0}\right)^{2}\right)}, \\
E=b s r, F=\gamma \theta_{0} . & \pi_{R}^{H^{*}}=\frac{(1-\phi) \mu\left(\alpha-b c-b c_{l}-b s r\right)^{2}}{2\left(2 b \mu-\left(b s r+\gamma \theta_{0}\right)^{2}\right)} .
\end{aligned}
\end{aligned}
$$

where $\quad A=\phi \alpha+b c+b p_{l}+E-h_{r} E, B=-\phi \alpha+b c+$ $b p_{l}+E-h_{r} E, E=b s r, F=\gamma \theta_{0}$.

To achieve coordination between the online retailer and TPL, the optimal decision under the coordination contract should be consistent with the optimal decision under the centralized model, that is, $e^{H *}=e^{C *}, p^{H *}=p^{C *}$. At this time, the logistics service price $p_{l}$ is no longer a decision variable of TPL but a moderating variable.

Proposition 7. (1) Under the "two-way cost-sharing and benefit-sharing" contract, if the contract parameters satisfy $p_{l}=\phi c_{l}-(1-\phi) c, h_{e}=\phi$, and $h_{r}=1-\phi$, supply chain coordination can be achieved. (2) Under the "two-way cost sharing-revenue sharing" contract, if the contract parameters satisfy $2 b \mu\left(2 b \mu-\left(b s r+\gamma \theta_{0}\right)^{2}\right) /\left(4 b \mu-\left(b s r+\gamma \theta_{0}\right)^{2}\right)<\phi<$ $2 b \mu / 4 b \mu-\left(b s r+\gamma \theta_{0}\right)^{2}$, the Pareto improvement of the supply chain can be achieved, that is, $\pi_{R}^{H *}>\pi_{R}^{D *}, \pi_{L}^{H *}>\pi_{L}^{D^{*}}$.
Proposition 7 shows that under the coordination contract, the fresh e-commerce supply chain can achieve system optimization when the relevant parameters meet certain conditions. (1) TPL will give the online retailer a logistics service price lower than the transportation cost and may even have a negative value. The logistics service price $p_{l}$ has a linear relationship with the fresh-keeping cost-sharing ratio $h_{e}$. (2) TPL's share of compensation cost $h_{r}$ is equal to the online retailer's sales revenue ratio $1-\phi$. (3) After the coordination contract is implemented, supply chain coordination can be achieved by adjusting contract parameters, and both parties 
can achieve Pareto improvement. (4) With the increase of the basic quantity loss rate $r$ or the freshness sensitivity coefficient $\gamma$, the threshold value of the retailer's sales revenue ratio becomes larger. The specific setting of contract parameters also depends on the bargaining power between online retailers and TPL. Therefore, the two-way cost-sharing and revenuesharing contract can achieve supply chain coordination so that the retail price and fresh-keeping effort of fresh products can reach the optimal level and promote the coordinated development of the fresh e-commerce supply chain.

\section{Numerical Analysis}

To further analyze and verify the influence of factors such as basic quantity loss rate on the optimal fresh-keeping effort, product selling price, and profit of the fresh e-commerce supply chain, relevant parameters are set according to the model conditions: $\alpha=150, b=10, c=3, c_{l}=4, \quad s=15$, $\theta_{0}=1, \gamma=5$.

6.1. The Impact of Basic Quantity Loss Rater on Supply Chain. In this subsection, we mainly explore the change trends of the optimal fresh-keeping effort level, selling price, online retailer's profit, and TPL's profit with the basic quantity loss rate $r$. Set $\mu^{1}=40<\gamma \theta_{0} K / b, \mu^{2}=150 \in\left(\gamma \theta_{0} K / b, K(2 K+\right.$ $\left.\left.\sqrt{4 K^{2}+9 \gamma^{2} \theta_{0}^{2}}\right) / 9 b\right), \mu^{3}=350>K\left(2 K+\sqrt{4 K^{2}+9 \gamma^{2} \theta_{0}^{2}}\right) / 9 b$, and $\mu^{1}, \mu^{2}<K\left(49 K-8 \gamma \theta_{0}+7 \sqrt{49 K^{2}-} 16 \gamma \theta_{0}\left(\alpha-b c-b c_{l}-\right.\right.$ $\left.\left.3 \gamma \theta_{0}\right)\right) / 384 b=182.8, \mu^{3}>182.8$.

Figure 2 indicates: (1) Figure 2(a) shows that when the fresh-keeping cost is low, fresh-keeping effort level and retail price always increase with the increase of $r$ under the centralized and decentralized model. (2) Figure 2(b) shows that when the fresh-keeping cost is within a certain range, the retail price under the decentralized model will increase as $r$ increases; the sales price under the centralized model will show an inverted $\mathrm{U}$-shaped trend as $r$ increases. (3) Figure 2(c) shows that when the fresh-keeping cost is high, the fresh-keeping effort and selling price of the centralized model increase as $r$ increases; the fresh-keeping effort under the decentralized model first increases and then decreases with the $r$ increase, and the sales price always increases with the $r$ increase. (4) With the $r$ increase, supply chain profits invariably show a downward trend.

It can be seen that under the centralized model, the greater the basic quantity loss rates of fresh products, the stronger the product's perishability. TPL will improve the level of fresh-keeping effort all the time, and the retail price depends on the value of the quantity loss rate. When the fresh-keeping cost is within a certain range and the quantity loss rate is small, the effect of increasing fresh-keeping effort on reducing the proportion of compensation is weak. The marginal cost of improving preservation is higher than the marginal revenue, so a price increase strategy is adopted; when the loss rate is higher than a certain threshold value, a sufficiently high preservation effort level can effectively reduce quantity loss. Therefore, the online retailer's compensation cost is sufficiently low, which in turn enables them to provide lower sales prices. When the cost of preservation is high, online retailers choose a price increase strategy to make up for the cost of preservation.

Under the decentralized model, when the quantity loss rate increases, TPL will not necessarily increase the level of fresh-keeping effort. TPL will increase the fresh-keeping effort level when the fresh-keeping cost is low; TPL makes decisions based on the size of the basic quantity loss rate when the fresh-keeping cost is high. When fresh-keeping effort and the quantity loss rate are at a high level, TPL will reduce the fresh-keeping effort, and the online retailer will adopt a price increase strategy. It can also be found that as the basic quantity loss rate increases, the profits of online retailers and TPL consistently decrease.

6.2. The Impact of Compensation Cost Coefficient s on Supply Chain. In order to analyze the impact of compensation cost coefficient $s$ on optimal decision and profit of the fresh e-commerce supply chain, set $r=0.2, \mu=150$ and use $s$ as the abscissa to obtain Figure 3.

Figure 3 shows that (1) TPL will increase preservation effort as $s$ increases; (2) the sales price trend of the decentralized decision and the centralized decision is opposite, and the sales price under decentralized decision increases with the increase of $s$. The sales price under centralized decision will decrease with the increase of $s$. (3) The profits of the online retailer and TPL will both decrease. When the compensation cost coefficient increases, online retailers will increase the price, and TPL invests in lower fresh-keeping effort under the decentralized model, which will cause consumers to reduce purchases. Therefore, the profit of the supply chain decreases with the increase in $s$. The supply chain under the centralized model will provide higher fresh-keeping effort and lower sales price to stimulate demand and implement a "high-quality and low-price" strategy. Therefore, even if the compensation cost coefficient increase, the supply chain profits will decline more slowly.

6.3. The Impact of Coordination Contract Parameters on Supply Chain's Profit. In order to further understand the effectiveness of the "two-way cost-sharing-revenue sharing" coordination contract, after the implementation of the coordination contract, the optimal decision and profit changes of online retailers and TPL are tested. Table 2 is obtained according to the parameters in Section 6.2.

Table 2 shows that after the implementation of the coordination contract, as the revenue-sharing ratio $\varphi$ increases, the online retailer's profit will increase monotonically, while the TPL's profit will decrease monotonically. Therefore, the online retailer and TPL's profits are the same increments when $\phi$ is in a certain range, that is, $\varphi \epsilon(0.234,0.268)$. At this time, not only can the supply chain of fresh e-commerce be coordinated, but also Pareto improvement can be achieved. It is also found that with the increase of $\phi$, the online retailer will share more fresh-keeping costs. Meanwhile, TPL will set higher logistics service prices to counteract the shared compensation costs. 

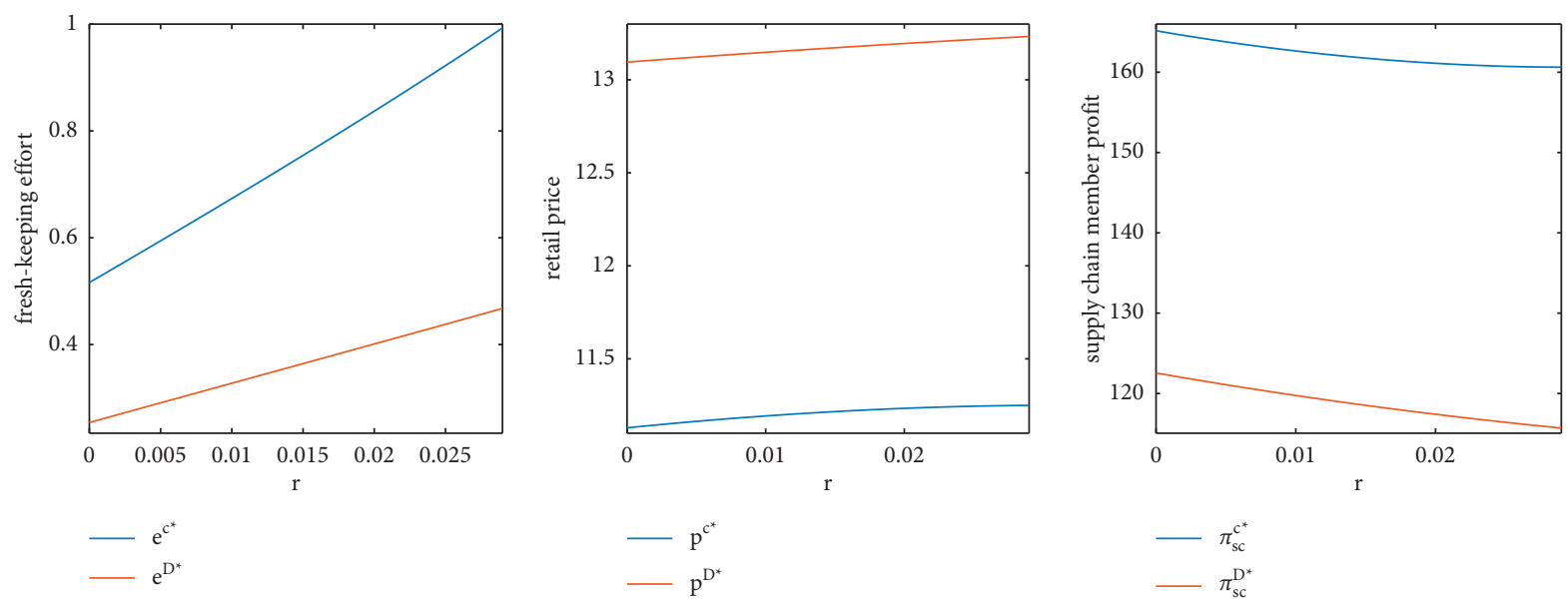

(a)
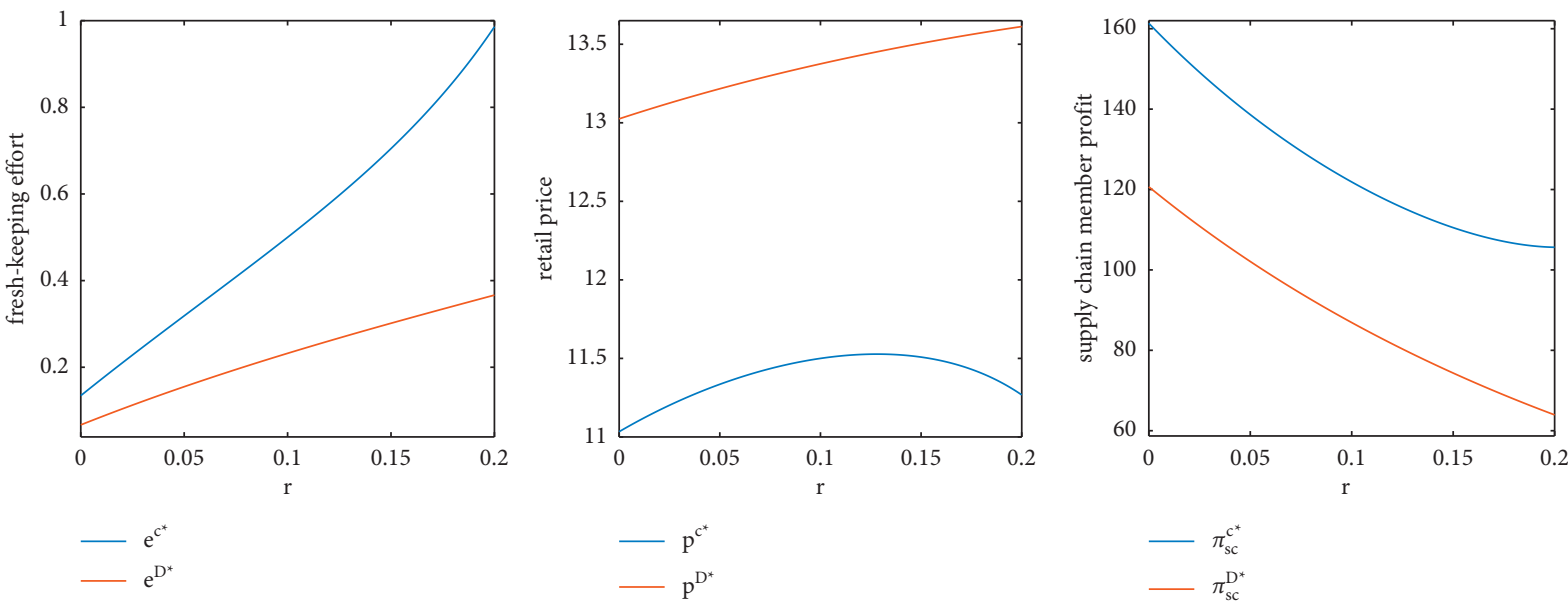

(b)
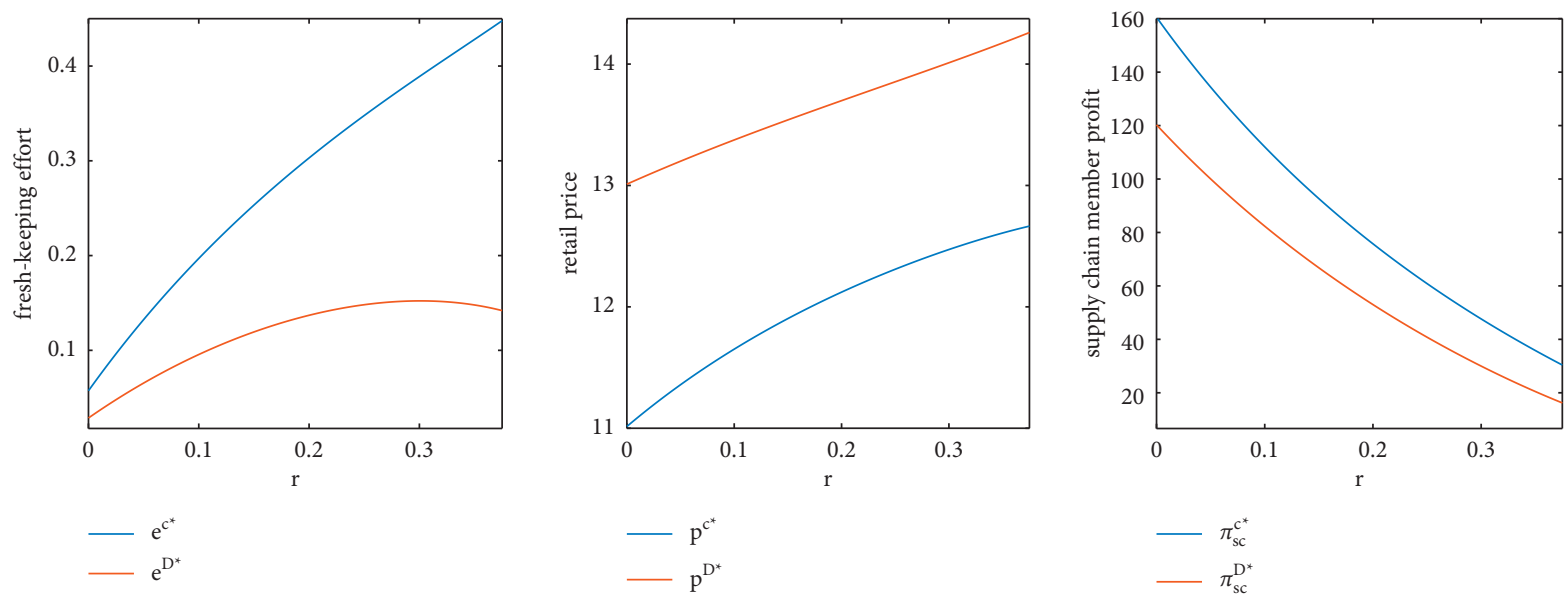

(c)

FIGURE 2: The optimal fresh-keeping effort, retail price, and supply chain profit as a function of $r$ : (a) $\mu^{1}=40$, (b) $\mu^{2}=150$, and (c) $\mu^{3}=350$.

\section{Conclusions}

In recent years, online retailers are willing to cooperate with a TPL provider to decrease quality loss and quantity loss. Motivated by this, this paper first establishes two decisionmaking modes, then comparatively analyzes the equilibrium decisions of the fresh-keeping effort and the retail price, and further explores how to design contracts to achieve fresh e-commerce supply chain coordination. The main conclusions are as follows:

Under the centralized model, we find that the freshkeeping effort increases with the increase in the basic 


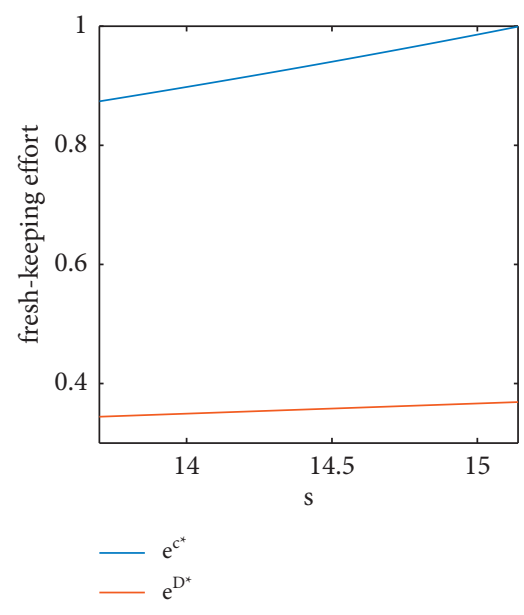

(a)

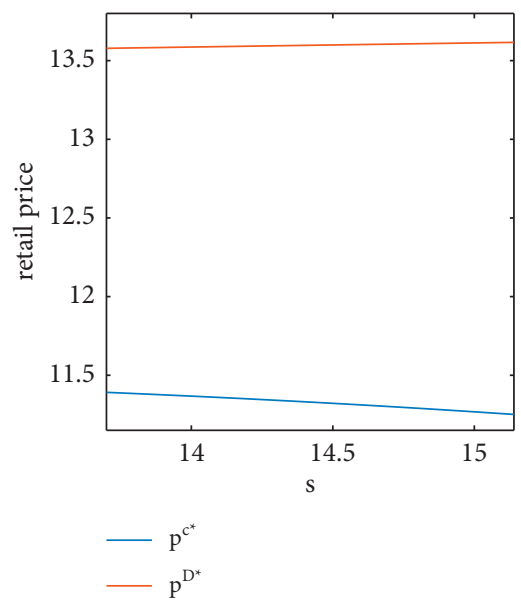

(b)

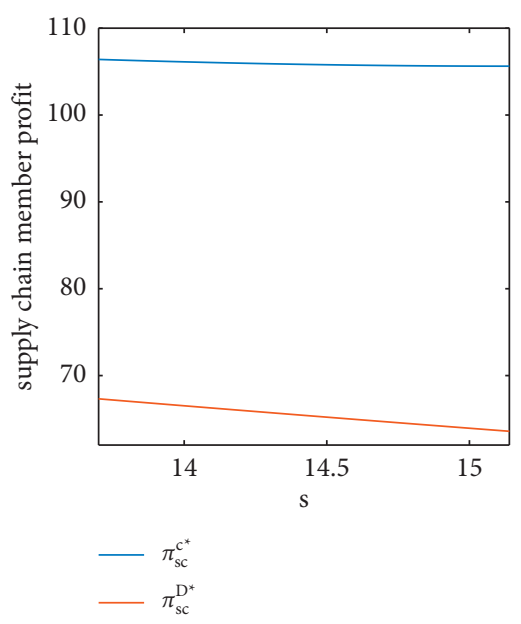

(c)

FIgURE 3: (a) The optimal fresh-keeping effort, (b) retail price, and (c) supply chain profit as a function of $s$.

TABLE 2: The change of supply chain's profit.

\begin{tabular}{lcccccccccc}
\hline Models & $\phi$ & $h_{e}$ & $h_{r}$ & $e$ & $p_{l}$ & $p$ & $D$ & $\pi_{R}$ & $\pi_{L}$ & $\pi_{S C}$ \\
\hline Centralized & N/A & N/A & N/A & 0.98 & N/A & 11.26 & 42.25 & N/A & N/A & 105.63 \\
Decentralized & N/A & N/A & N/A & 0.36 & 7.141 & 13.61 & 15.70 & 24.67 & 39.26 & 63.93 \\
& 0.25 & 0.25 & 0.75 & 0.98 & -1.25 & 11.26 & 42.25 & 26.41 & 79.22 & 105.63 \\
& 0.35 & 0.35 & 0.65 & 0.98 & -0.55 & 11.26 & 42.25 & 36.97 & 68.66 & 105.63 \\
Coordination & 0.45 & 0.45 & 0.55 & 0.98 & 0.15 & 11.26 & 42.25 & 47.53 & 58.10 & 105.63 \\
& 0.55 & 0.55 & 0.45 & 0.98 & 0.85 & 11.26 & 42.25 & 58.10 & 47.53 & 105.63 \\
\hline
\end{tabular}

quantity loss rate and the freshness sensitivity. The retail price increases monotonically in quantity loss rate when the fresh-keeping cost is low or high, and the retail price is nonmonotone in quantity loss rate when the fresh-keeping cost is within a certain range. Specifically, low or high quantity loss rate yields low retailing price. We also find that the retail price decreases monotonically with the increase in freshness sensitivity when the fresh-keeping cost is low. Instead, for high fresh-keeping costs, the retail price will first decrease and then increase with the improvement of freshness sensitivity.

Under the decentralized model, the retail price rises in the basic quantity loss rate and freshness sensitivity, and fresh-keeping effort increases in freshness sensitivity, while the TPL faces the choice of whether to improve freshkeeping effort in the basic quantity loss rate. As the basic quantity loss rate increases, the TPL's preference lies in a freshness promotion strategy with a low fresh-keeping cost. Instead of low values, high values of fresh-keeping effort cost leave the TPL to increase the fresh-keeping effort first and then reduce the fresh-keeping effort.

Finally, we design a two-way cost-sharing and revenue-sharing contract that can effectively coordinate the profits of supply chain members and achieve Pareto improvement.

Our work summarizes the following management insights based on the results obtained. First, regardless of whether it is in a centralized or a decentralized decisionmaking model, TPL should realize that the higher the freshness of the product, the larger the market size. Second, as the product's perishability and freshness sensitivity coefficient have a nonmonotonic impact on product prices, the online retailer flexibly sets prices according to the perishability and freshness sensitivity coefficient of different products. Third, both the online retailer and TPL ought to realize that it is beneficial to assume part of each other's responsibilities under certain conditions.

This article takes the situation of complete information sharing as the premise and can further study how to coordinate the fresh e-commerce supply chain in the situation of incomplete information sharing. In addition, some of the assumptions in this article are parsimonious. For example, the compensation ratio is only affected by preservation efforts, without considering issues such as delivery time, whether the logistics personnel operate in a standardized manner, and consumer reputation affects the compensation ratio. These are also directions worthy of follow-up research.

\section{Appendix}

Proofs. of Lemma 1. Under the centralized model, the online retailer and TPL are regarded as one decision-making 
organization. Therefore, from the perspective of maximizing the profit of the supply chain system, we obtain $\partial \pi_{S C}^{C} / \partial e=$ $s r\left(\alpha-b p+\gamma \theta_{0} e\right)-\gamma \theta_{0}\left(p-c-c_{l}\right)-\mu e-\gamma \theta_{0} s r(1-e)$ and $\partial \pi_{S C}^{C} / \partial p=\alpha+\gamma \theta_{0} e_{l}-b\left(2 p-c-c_{l}\right)+b s r(1-e)$. We define the Hessian matrix of $\pi_{\mathrm{SC}}^{\mathrm{C}}$ as $H_{1}$. $H_{1}=\left[\begin{array}{cc}-2 b & \gamma \theta_{0}-b s r \\ \gamma \theta_{0}-b s r & -\mu+2 \gamma \theta_{0} s r\end{array}\right]$, since $-2 b<0$, with the assumption, we have $\mu>\mu^{C 1}=\left(b s r+\gamma \theta_{0}\right)^{2} / 2 b$. The Hessian matrix is negative definite. Therefore, the profit $\pi_{S C}^{C}$ is joint concave in $(p, e)$. Solving the first-order condition $\partial \pi_{S C}^{C} / \partial e=0$ for $e, \partial \pi_{S C}^{C} / \partial p=0$ for $p$, we obtain the optimal fresh-keeping efforts $e^{C *}=\left(b s r+\gamma \theta_{0}\right)\left(\alpha-b c-b c_{l}-b s r\right) / 2 b \mu-\left(b s r+\gamma \theta_{0}\right)^{2}$ and retail price $p^{C *}=\left(\mu-s r\left(b s r+\gamma \theta_{0}\right)\right) \quad(\alpha-b c$ $\left.-b c_{l}-b s r\right) / 2 b \mu-\left(b s r+\gamma \theta_{0}\right)^{2}+c+c_{l}+s r$. Substituting $e^{C *}, p^{C *}$ into $\pi_{S C}^{C}, D^{C}$, we obtain $\pi_{S C}^{C *}, D^{C *}$. Lemma 1 characterizes the existence of a solution under the centralized model if $\mu \geq \max \left(\mu^{C 2}, \mu^{C 3}\right)$. Note that the assumption $\mu \geq \mu^{C 2}$ ensures that the online retailer is profitable. Meanwhile, $\mu \geq \mu^{C 3}$ ensures that fresh-keeping effort satisfies $e \leq 1$. If $\mu<\mu^{C 3}$, the fresh-keeping effort level equals the upper bound 1 , where the quantity loss of the online retailer will be zero. Hence, we focus on the case where there is quantity loss. Since $\mu^{C 3} \geq \mu^{C 1}$, the condition for the existence of the optimal solution is $\mu>\max \left(\mu^{\mathrm{C} 2}, \mu^{\mathrm{C} 3}\right)$.

Proofs. Lemma 2. Taking the second-order condition of equation (3) with respect to $p$, we obtain $\partial^{2} \pi_{R}^{D} / \partial p^{2}=-2 b<0$, where $\pi_{R}^{D}$ is concave in $p$. Solving the first-order condition $\partial \pi_{R}^{D} / \partial p^{2}=\alpha-b\left(2 p-c-p_{l}\right)+\gamma \theta_{0} e+$ $b s r(1-e)=0$ for $p$, we obtain $p_{1}=\alpha+b\left(c+p_{l}\right)+$ $\gamma \theta_{0} e+b s r(1-e) / 2 b$. Substituting $p_{1}$ into equation (3), we obtain $\pi_{L}^{D}\left(e, p_{l}\right)$. Taking the first-order condition of $\pi_{L}^{D}\left(e, p_{l}\right)$ with respect to $\left(e, p_{l}\right)$. We obtain $\partial \pi_{L}^{D} / \partial e=$ $1 / 2\left(b s r+\gamma \theta_{0}\right)\left(p_{l}-c_{l}\right)-\mu e . \partial \pi_{L}^{D} / \partial p=1 / 2\left(\alpha-b\left(p_{l}-c_{l}\right)-\right.$ $\left.b\left(c+p_{l}\right)+1 / 2 \gamma \theta_{0} e-b s r(1-e)\right)$. Let $H_{2}$ be the Hessian matrix of $\pi_{L}^{D}$ and $H_{2}=\left[\begin{array}{cc}-\mu & 1 / 2\left(b s r+\gamma \theta_{0}\right) \\ 1 / 2\left(b s r+\gamma \theta_{0}\right) & -b\end{array}\right]$. Since $-\mu<0$, we have $\mu>\mu^{D 1}=\left(b s r+\lambda \theta_{0}\right)^{2} / 4 b$. The Hessian matrix is negative definite. Therefore, the profit $\pi_{L}^{D}$ is joint concave in $\left(e, p_{l}\right)$. Solving the first-order conditions $\partial \pi_{L}^{D} / \partial e=0, \partial \pi_{L}^{D} / \partial p=0$ for $\mathrm{e}, \mathrm{p}_{\mathrm{l}}$, we obtain $e^{D *}=\left(b s r+\gamma \theta_{0}\right)\left(\alpha-b c-b c_{l}-b s r\right) / 4 b \mu-\left(b s r+\gamma \theta_{0}\right)^{2}$, $p_{l}^{D^{*}}=2 \mu\left(\alpha-b c-b c_{l}-b s r\right) / 4 b \mu-\left(b s r+\gamma \theta_{0}\right)^{2}+c_{l}$

Based on $e^{D *}, p_{l}^{D^{*}}$, we derive equilibrium decision $p^{D^{*}}=$ $\left(3 \mu-s r\left(\gamma \theta_{0}+b s r\right)\right)\left(\alpha-b c-b c_{l}-b s r\right) / 4 b \mu-\left(b s r+\gamma \theta_{0}\right)^{2}+$ $c+c_{l}+s r$. Substituting the optimal decisions to $\pi_{R}^{D}$, $\pi_{L}^{D}, \pi_{S C}^{D}, D^{D}$, we obtain $\pi_{R}^{D *}, \pi_{L}^{D *}, \pi_{S C}^{D *}$, and $D^{D *}$. Similar to Lemma 1 , the condition for the existence of the optimal solution is $\mu>\max \left(\mu^{D 2}, \mu^{D 3}\right)$.

Proofs. of Proposition 1. To simplify the expression, let $K=\alpha-b c-b c_{l}+\gamma \theta_{0}, Q=\alpha-b c-b c_{l}-b s r$. From Lemma 1 , we have $d e^{C^{*}} / d r=b s\left(2 b \mu\left(2 b \mu-\quad\left(b\left(Q-\gamma \theta_{0}\right)+\right.\right.\right.$ $\left.\left.\left.\left.\left(b s r+\gamma \theta_{0}\right)^{2} K\right)\right) \quad / \quad s r+\gamma \theta_{0}\right)^{2}\right)^{2}>0 . d D^{C} / d r=-b^{2} s \mu(2 b \mu-$ $\left.\left(b s r+\gamma \theta_{0}\right)^{2}+2\left(b s r+\gamma \theta_{0}\right) Q\right) /\left(2 b u-\left(b s r+\gamma \theta_{0}\right)^{2}\right)^{2}<0$ and $d \pi_{S G}^{C^{*}} / d r=-b u s Q\left(2 b u-\left(b s r+\gamma \theta_{0}\right) K\right) / \quad(2 b u-(b s r+$ $\left.\left.\gamma \theta_{0}\right)^{2}\right)^{2}<0 . d p^{C^{*}} / d r=M_{1} s /\left(2 b u-\left(b s r+\gamma \theta_{0}\right)^{2}\right)^{2}$; the sign of $d p^{C *} / d r$ is the same as that of $\mathrm{M}_{1}$ such that we will mainly analyze $\quad M_{1}$, where $\quad M_{1}=2 b^{2} \mu\left(\mu-s r\left(K+\gamma \theta_{0}\right)\right)+$ $\gamma \theta_{0}\left(b s r+\gamma \theta_{0}\right)^{2} K+b \mu\left(b^{2} s^{2} r^{2}-3 \gamma^{2} \theta^{2}\right)$ and $d M_{1} / d r=2 b s$ $\left(-b \mu Q+\gamma \theta_{0}\left(\left(b s r+\gamma \theta_{0}\right) K-2 b \mu\right)\right)<0$; if $\mu \geq K^{2} / 2 b$, then $M_{1}>0$, we derive $d p^{C *} / d r>0$. If $\mu<K^{2} / 2 b$; let $M_{1}=0$, we have $r_{1}=\left(b \mu-\gamma^{2} \theta_{0}^{2}\right) K+b \mu \gamma \theta_{0}-\sqrt{b \mu\left(b \mu-2 \gamma^{2} \theta_{0}^{2}\right)} \quad\left(K^{2}-\right.$ $2 b \mu) / b s\left(b \mu+\gamma \theta_{0} K\right)$. From $\mu \geq \mu^{C 2}=s r\left(b s r+\gamma \theta_{0}\right)$, we have $r_{2}=\sqrt{4 b \mu+\gamma^{2} \theta_{0}^{2}}-\gamma \theta_{0} / 2 b s$. From $\mu \geq \mu^{C 3}=\left(b s r+\gamma \theta_{0}\right)$ $K / 2 b$, we have $r_{3}=2 b \mu-\gamma \theta_{0} K / b s K$. From $Q=\alpha-$ $b c-b c_{l}-b s r>0$, we have $r_{4}=\alpha-b c-b c_{l} / b s$, so $r \leq \min \left(r_{2}, r_{3}, r_{4}, 1\right)$. Comparing the size of $r_{1}$ and $\min \left(r_{2}, r_{3}, r_{4}, 1\right)$, we obtain: if $K\left(2 K+\sqrt{4 K^{2}+9 \gamma^{2} \theta_{0}^{2}}\right) /$ $9 b<\mu<K^{2} / 2 b$, then $r_{1}>r_{2}=\min \left(r_{2}, r_{3}, r_{4}, 1\right)$, we derive $d p^{C *} / d r>0 ; \quad$ if $\quad \gamma \theta_{0} K / b<\mu<K\left(2 K+\sqrt{4 K^{2}+9 \gamma^{2} \theta_{0}^{2}}\right) / 9 b$, then $r_{1}<r_{2}=\min \left(r_{2}, r_{3}, r_{4}, 1\right)$, when $0<r<r_{1}$, we derive $d p^{C *} / d r>0$; when $r_{1}<r<r_{2}$, we derive $d p^{C *} / d r<0$; if $\left(b s r+\gamma \theta_{0}\right) K / 2 b<\mu<\gamma \theta_{0} K / b$, then $r_{1}>r_{3}=\min \left(r_{2}, r_{3}\right.$, $\left.r_{4}, 1\right)$, we derive $d p^{C *} / d r>0$.

In summary, for the retail price, when $\gamma \theta_{0} K / b$ $<\mu<K\left(2 K+\sqrt{4 K^{2}+9 \gamma^{2} \theta_{0}^{2}}\right) / 9 b$, if $0<r<r_{1}$, we have $d p^{C *} / d r>0$; if $\mathrm{r}_{1}<\mathrm{r}<\mathrm{r}_{2}$, we have $d p^{C *} / d r<0$. When $\mu \in\left(\left(b s r+\gamma \theta_{0}\right) K / 2 b, \gamma \theta_{0} K / b\right) \cup\left(K\left(2 K+\sqrt{4 K^{2}+9 \gamma^{2} \theta_{0}^{2}}\right) /\right.$ $9 b,+\infty)$, we have $d p^{C *} / d r>0$.

Proofs. of Proposition 2 From Lemma 2, we have $d e^{D *} / d r=b s M_{2} /\left(4 b \mu-\left(b s r+\gamma \theta_{0}\right)^{2}\right)^{2}, \quad$ where $M_{2}=4 b \mu\left(Q-b s r-\gamma \theta_{0}\right)+\left(b s r+\gamma \theta_{0}\right)^{2} K$. Let $M_{2}=0$, we have $r_{11}=4 b \mu-2 \sqrt{b \mu\left(4 b \mu-K^{2}\right)}-\gamma \theta_{0} K / b s K$. Similar to Proofs of Proposition $1 r \leq \min \left(r_{22}, r_{33}, r_{44}, 1\right)$, where $r_{22}=$ $\sqrt{12 b \mu+\gamma^{2} \theta_{0}^{2}}-\gamma \theta_{0} / 2 b s, \quad r_{33}=4 b \mu-\gamma \theta_{0} K / b s K, r_{44}=\alpha-$ $b c-b c_{l} / b s$. When $\quad \mu<K\left(49 K-8 \lambda \theta_{0}+7\right.$ $\left.\sqrt{49 K^{2}-16 \gamma \theta_{0}\left(K-4 \gamma \theta_{0}\right)}\right) / 384 b$, we have $d e^{D *} / d r>0$; when $\quad \mu>K\left(49 K-8 \gamma \theta_{0}+7 \sqrt{49 K^{2}-16 \gamma \theta_{0}\left(K-4 \gamma \theta_{0}\right)} /\right.$ $384 b$, if $0<r<r_{11}$, then $d e^{D *} / d r>0$; if $r_{11}<r<r_{22}$, then $d e^{D *} / d r<0 . \quad d p_{l} / d r=2 b \mu s\left(\left(b s r+\gamma \theta_{0}\right)(K+Q)-4 b \mu\right) /$ $\left(4 b \mu-\left(b s r+\gamma \theta_{0}\right)^{2}\right)^{2}<0 . \quad d p^{D *} / d r=4 b^{2} \mu^{2}+$ $\left(\gamma \theta_{0}\left(b s r+\gamma \theta_{0}\right)^{2}-2 b \mu \quad\left(b s r-\gamma \theta_{0}\right)\right) K+b \mu\left(\left(b s r-\gamma \theta_{0}\right)^{2}+\right.$ $\left.5 \gamma^{2} \theta_{0}^{2}\right) / \quad\left(4 b \mu-\left(b s r+\gamma \theta_{0}\right)^{2}\right)^{2} s>0 . \quad d D^{D} / d r=-b^{2} s \mu(4 b \mu-$ $\left.\left(b s r+\gamma \theta_{0}\right)^{2}+2\left(b s r+\gamma \theta_{0}\right) Q\right) / \quad\left(4 b \mu-\left(b s r+\gamma \theta_{0}\right)^{2}\right)^{2}<0$. $d \pi_{R}^{D *} / d r=2 b^{2} \mu^{2} s Q\left(\left(b s r+\gamma \theta_{0}\right)(K+Q)-4 b \mu\right) / \quad(4 b \mu-$ $\left.\left(b s r+\gamma \theta_{0}\right)\right)^{3}<0 . d \pi_{L}^{D *} / d r=-b \mu s Q\left(4 b \mu-\left(b s r+\gamma \theta_{0}\right) K\right) /$ $\left(4 b \mu-\left(b s r+\gamma \theta_{0}\right)^{2}\right)^{2}<0$.

Proofs. of Proposition 3 From Lemma 1, we have $d e^{C *} / d \gamma=$ $\theta_{0} Q\left(2 b \mu+\left(b s r+\gamma \theta_{0}\right)^{2}\right) /\left(2 b \mu-\left(b s r+\gamma \theta_{0}\right)^{2}\right)^{2}>0 \quad$ and $d \pi_{S C}^{C *} / d \gamma=\theta_{0} \mu Q^{2}\left(b s r+\gamma \theta_{0}\right) /\left(2 b \mu-\left(b s r+\gamma \theta_{0}\right)^{2}\right)^{2}>0$. For the retail price, $d p^{C *} / d \gamma=\theta_{0} Q M_{3} /\left(2 b \mu-\left(b s r+\gamma \theta_{0}\right)^{2}\right)^{2}$, where $M_{3}=2 \mu \gamma \theta_{0}-s r\left(b s r+\gamma \theta_{0}\right)^{2}$. Similar to Proofs of 
Proposition 1 , let $M_{3}=0$, we have $\gamma_{1}=\mu-b s^{2} r^{2}$ $-\sqrt{\mu\left(\mu-2 b s^{2} r^{2}\right)} / s r \theta_{0}$. Since $\mu>\max \left(\mu^{C 2}, \mu^{C 3}\right)$, there exist $\gamma<\gamma^{*}=\sqrt{8 b \mu+Q^{2}}+b c+b c_{l}-\alpha-b s r / 2 \theta_{0}$. When $\mu \leq s r$ $\left(\sqrt{Q^{2}+4 b^{2} s^{2} r^{2}}+2 b s r\right) / 2$, we have $d p^{C *} / d \gamma<0$; when $\mu>s r\left(\sqrt{Q^{2}+4 b^{2} s^{2} r^{2}}+2 b s r\right) / 2$, if $0<\gamma<\gamma_{1}$, then $d p^{C *} / d \gamma<0$; if $\gamma_{1}<\gamma<\gamma^{*}$, then $d p^{C *} / d \gamma>0$.

Proofs. of Proposition 4 From Lemma 2, we derive $d e^{D *} / d \gamma=\theta_{0} Q\left(4 b \mu+\left(b s r+\gamma \theta_{0}\right)^{2}\right) / \quad\left(4 b \mu-\left(b s r+\gamma \theta_{0}\right)^{2}\right)^{2}$ >0. $\quad d p_{l}^{D *} / d \gamma=4 \theta_{0} \mu \mathrm{Q}\left(b s r+\gamma \theta_{0}\right) /\left(4 b \mu-\left(b s r+\gamma \theta_{0}\right)^{2}\right)^{2}$ >0. $\quad d p^{D *} / d \gamma=\theta_{0} Q\left(s r\left(2 b \mu-\left(b s r+\gamma \theta_{0}\right)^{2}\right)+6 \gamma \theta_{0} \mu\right) /$ $\left(2 b \mu-\left(b s r+\gamma \theta_{0}\right)^{2}\right)^{2}>0 . d \pi_{R}^{D *} / d \gamma=4 \theta_{0} b \mu^{2} Q\left(b s r+\gamma \theta_{0}\right) /$ $\left(4 b \mu-\left(b s r+\gamma \theta_{0}\right)\right)^{3}>0 . \quad d \pi_{L}^{D *} / d \gamma=\theta_{0} \mu Q^{2}\left(b s r+\gamma \theta_{0}\right) /$ $\left(4 b \mu-\left(b s r+\gamma \theta_{0}\right)\right)^{2}>0$.

Proofs. of Proposition 5 Based on Lemmas 1 and 2, it follows: $e^{C *}-e^{D *}=2 b \mu\left(b s r+\gamma \theta_{0}\right) Q /\left(2 b \mu-\left(b s r+\gamma \theta_{0}\right)^{2}\right)$ $\left(4 b \mu-\left(b s r+\gamma \theta_{0}\right)^{2}\right)>0 . \quad p^{C *}-p^{D *}=-2 \mu\left(b \mu-b s r \gamma \theta_{0}+\right.$ $\left.\gamma^{2} \theta_{0}^{2}\right) Q /\left(2 b \mu-\left(b s r+\gamma \theta_{0}\right)^{2}\right)\left(4 b \mu-\left(b s r+\gamma \theta_{0}\right)^{2}\right)<0 . D^{C}-$ $D^{D}=2 b^{2} \mu^{2} Q /\left(2 b \mu-\left(b s r+\gamma \theta_{0}\right)^{2}\right)\left(4 b \mu-\left(b s r+\gamma \theta_{0}\right)^{2}\right)>0$. $\pi_{S C}^{C *}-\quad \pi_{S C}^{D *}=2 b^{2} \mu^{3} Q^{2} /\left(2 b \mu-\left(b s r+\gamma \theta_{0}\right)^{2}\right)(4 b \mu-\quad(b s r+$ $\left.\gamma\left(\theta_{0}\right)^{2}\right)^{2}>0$.

\section{Data Availability}

The data used to support the findings of this paper are included within the article (Numerical Analysis section).

\section{Conflicts of Interest}

The authors declare that there are no conflicts of interest.

\section{Acknowledgments}

This research was funded by the Natural Science Foundation of Heilongjiang Province (grant no. LH2021G014), Key Research Projects of Economic and Social Development in Heilongjiang Province (grant no. 20411), Central Government Supporting the Reform and Development of HighLevel Talents in Local Colleges and Universities (grant no. 2020GSP13), and Key Special Sub-projects of the National Key R\&D Plan (grant no. 2018YFB1402500).

\section{References}

[1] B. Bai, K. Zhao, and X. Li, "Application research of nanostorage materials in cold chain logistics of e-commerce fresh agricultural products," Results in Physics, vol. 13, Article ID 102049, 2019.

[2] IResearch, "China fresh e-commerce industry research report,” 2021, https://www.iresearch.com.cn/Detail/report? id $=3776 \&$ isfree $=0$.

[3] H. Zhao, S. Liu, C. Tian, G. Yan, and D. Wang, "An overview of current status of cold chain in China," International Journal of Refrigeration, vol. 88, pp. 483-495, 2018.

[4] J. Chen, Z. Tian, and W. Hang, "Optimal ordering and pricing policies in managing perishable products with quality deterioration," International Journal of Production Research, vol. 59, no. 15, pp. 4472-4494, 2021.

[5] U. S. eMarketer, "Internet users whose concern about temperature and freshness of fresh and frozen food items is a reason they have not ordered them online for home delivery," 2019, https://www.emarketer.com/chart/230850/us-internetusers-whose-concern-about-temperature-freshness-of-freshfrozen-food-items-reason-they-have-not-ordered-themonline-home-delivery-aug-2019-of-respondents-by-age.

[6] Y. Yu and T. Xiao, "Pricing and cold-chain service level decisions in a fresh agri-products supply chain with logistics outsourcing," Computers \& Industrial Engineering, vol. 111, pp. 56-66, 2017.

[7] C. Wang and X. Chen, "Option pricing and coordination in the fresh produce supply chain with portfolio contracts," Annals of Operations Research, vol. 248, no. 1-2, pp. 471-491, 2017.

[8] B. He, X. Gan, and K. Yuan, "Entry of online presale of fresh produce: a competitive analysis," European Journal of Operational Research, vol. 272, no. 1, pp. 339-351, 2019.

[9] X.-Y. Wu, Z.-P. Fan, and B.-B. Cao, "An analysis of strategies for adopting blockchain technology in the fresh product supply chain," International Journal of Production Research, pp. 1-18, 2021.

[10] C.-Y. Dye and C.-T. Yang, "Optimal dynamic pricing and preservation technology investment for deteriorating products with reference price effects," Omega, vol. 62, pp. 52-67, 2016.

[11] C. S. F. Daily, "Express and Noah's Ark signed an in-depth cooperation agreement," 2020, https://caijing.chinadaily.com. cn/a/202004/20/WS5e9d22c9a310c00b73c783c2.html.

[12] Y. Zhang, F. Rong, and Z. Wang, "Research on cold chain logistic service pricing-based on tripartite Stackelberg game," Neural Computing and Applications, vol. 32, no. 1, pp. 213222, 2020.

[13] L. Feng, W. C. Wang, J. T. Teng, and L. E. Cárdenas-Barróne, "Pricing and lot-sizing decision for fresh goods when demand depends on unit price, displaying stocks and product age under generalized payments," European Journal of Operational Research, vol. 296, no. 3, pp. 940-952, 2022.

[14] W. Shui and M. Li, "Integrated pricing and distribution planning for community group purchase of fresh agricultural products," Scientific Programming, vol. 2020, Article ID 8839398, 2020.

[15] D. Nakandala, H. Lau, and J. Zhang, "Pricing of fresh food enterprises in different market structures," Enterprise Information Systems, vol. 15, no. 3, pp. 373-394, 2021.

[16] T. Fan, C. Xu, and F. Tao, "Dynamic pricing and replenishment policy for fresh produce," Computers \& Industrial Engineering, vol. 139, Article ID 106127, 2020.

[17] K.-M. Wang and Z.-J. Ma, "Age-based policy for blood transshipment during blood shortage," Transportation Research Part E: Logistics and Transportation Review, vol. 80, pp. 166-183, 2015.

[18] M. Liu, B. Dan, and S. Ma, "Optimal strategies and coordination of fresh e-commerce supply chain considering freshness-keeping effort and value-added service," Chinese Journal of Management Science, vol. 28, no. 8, pp. 76-88, 2020.

[19] L. Yang and R. Tang, "Comparisons of sales modes for a fresh product supply chain with freshness-keeping effort," Transportation Research Part E: Logistics and Transportation Review, vol. 125, pp. 425-448, 2019.

[20] Q. Zheng, M. Wang, and F. Yang, "Optimal channel strategy for a fresh produce E-commerce supply chain," Sustainability, vol. 13, no. 11, 2021.

[21] Q. Zheng, L. Zhou, T. Fan, and P. Ieromonachou, "Joint procurement and pricing of fresh produce for multiple retailers with a quantity discount contract," Transportation 
Research Part E: Logistics and Transportation Review, vol. 130, pp. 16-36, 2019.

[22] X. Cai, J. Chen, Y. Xiao, and X. Xu, "Optimization and coordination of fresh product supply chains with freshnesskeeping effort," Production and Operations Management, vol. 19, no. 3, pp. 261-278, 2010.

[23] C. Liu, C. Chen, Q. Zhou, and J. Mu, "Modelling dynamic freshness-keeping effort over a finite time horizon in a twoechelon online fresh product supply chain," European Journal of Operational Research, vol. 293, no. 2, pp. 511-528, 2021.

[24] Y. G. Feng, Y. Hu, and L. He, "Research on coordination of fresh agricultural product supply chain considering freshkeeping effort level under retailer risk avoidance," Discrete Dynamics in Nature and Society, vol. 2021, Article ID 5527215, 2021.

[25] B. Yan, Y.-R. Chen, and S.-Y. He, "Decision making and coordination of fresh agriculture product supply chain considering fairness concerns," RAIRO-Operations Research, vol. 54, no. 4, pp. 1231-1248, 2020.

[26] J. Zhang, G. Liu, Q. Zhang, and Z. Bai, “Coordinating a supply chain for deteriorating items with a revenue sharing and cooperative investment contract," Omega, vol. 56, pp. 37-49, 2015.

[27] H. Mohammadi, M. Ghazanfari, M. Saman Pishvaee, and E. Teimoury, "Fresh-product supply chain coordination and waste reduction using a revenue-and-preservation-technology-investment-sharing contract: a real-life case study," Journal of Cleaner Production, vol. 213, pp. 262-282, 2019.

[28] Y. He, H. Huang, and D. Li, "Inventory and pricing decisions for a dual-channel supply chain with deteriorating products," Operational Research, vol. 20, no. 3, pp. 1461-1503, 2018.

[29] B. Gu, Y. Fu, and J. Ye, "Joint optimization and coordination of fresh-product supply chains with quality-improvement effort and fresh-keeping effort," Quality Technology \& Quantitative Management, vol. 18, no. 1, pp. 20-38, 2021.

[30] T. Shao and X. Lv, "To implant consumption experience for E-commerce of fresh agricultural products based on consumer sovereignty," Chinese Journal of Management Science, vol. 26, no. 08, pp. 118-126, 2018.

[31] Y. He, H. Huang, D. Li, C. Shi, and S. J. Wu, "Quality and operations management in food supply chains: a literature review," Journal of Food Quality, vol. 2018, Article ID 7279491, 14 pages, 2018.

[32] B. Shen, X. Xu, and S. Guo, "The impacts of logistics services on short life cycle products in a global supply chain," Transportation Research Part E: Logistics and Transportation Review, vol. 131, pp. 153-167, 2019.

[33] Y. Qin, J. Wang, and C. Wei, "Joint pricing and inventory control for fresh produce and foods with quality and physical quantity deteriorating simultaneously," International Journal of Production Economics, vol. 152, pp. 42-48, 2014.

[34] X. Cai, J. Chen, Y. Xiao, X. Xu, and G. Yu, "Fresh-product supply chain management with logistics outsourcing," Omega, vol. 41, no. 4, pp. 752-765, 2013.

[35] Q. Wu, Y. Mu, and Y. Feng, "Coordinating contracts for fresh product outsourcing logistics channels with power structures," International Journal of Production Economics, vol. 160, pp. 94-105, 2015.

[36] Y. Yu and T. Xiao, "Analysis of cold-chain service outsourcing modes in a fresh agri-product supply chain," Transportation Research Part E: Logistics and Transportation Review, vol. 148, p. 102264, 2021.

[37] X. Ma, S. Wanga, S. M. N. Islam, and X. Liu, "Coordinating a three-echelon fresh agricultural products supply chain considering freshness-keeping effort with asymmetric information," Applied Mathematical Modelling, vol. 67, pp. 337356, 2019.

[38] Z. Song and S. He, "Contract coordination of new fresh produce three-layer supply chain," Industrial Management \& Data Systems, vol. 119, 2018.

[39] B. C. Giri and B. R. Sarker, "Improving performance by coordinating a supply chain with third party logistics outsourcing under production disruption," Computers \& Industrial Engineering, vol. 103, pp. 168-177, 2017.

[40] P. Liu and S. Wang, "Logistics outsourcing of fresh enterprises considering fresh-keeping efforts based on evolutionary game analysis," IEEE Access, vol. 2021, Article ID 3056699, 2021.

[41] Q. Bai, M. Chen, and L. Xu, "Revenue and promotional costsharing contract versus two-part tariff contract in coordinating sustainable supply chain systems with deteriorating items," International Journal of Production Economics, vol. 187, pp. 85-101, 2017.

[42] X. Yang, G. Cai, C. A. Ingene, and J. Zhang, "Manufacturer strategy on service provision in competitive channels," Production and Operations Management, vol. 29, no. 1, pp. 72-89, 2020. 